\title{
Impact of low skeletal muscle mass index and perioperative blood transfusion on the prognosis for HCC following curative resection
}

Tomoaki Bekki ${ }^{1}$, Tomoyuki Abe ${ }^{1 *}$ (D), Hironobu Amano ${ }^{1,2}$, Minoru Hattori $^{3}$, Tsuyoshi Kobayashi ${ }^{2}$, Masahiro Nakahara ${ }^{1}$, Hideki Ohdan ${ }^{2}$ and Toshio Noriyuki, ${ }^{1,2}$

\begin{abstract}
Background: This study aimed to assess the prognostic factors including low skeletal muscle mass index (SMI) and perioperative blood transfusion for patients with hepatocellular carcinoma (HCC) following curative surgery.

Methods: This study included 139 patients with HCC who underwent hepatectomy between 2005 and 2016. Univariate and multivariate analyses were performed to identify variables associated with overall survival (OS) and recurrence-free survival (RFS).

Results: Low SMI was significantly related with poor OS, while blood transfusion had a strong impact on RFS. The male ratio and body mass index in the low SMI group were significantly higher than those in the high SMI group. There were no significant differences in age, virus etiology, laboratory data, liver function, tumor makers, and operative variables between the groups. Tumor factors such as tumor diameter, tumor number, poor differentiation, and intrahepatic metastasis (IM) did not significantly differ between the two groups. Operation time, intraoperative blood loss volume, and recurrence ratio were significantly higher in the blood transfusion group than in the nontransfusion group. IM was associated with poor OS and RFS.
\end{abstract}

Conclusions: Low SMI and blood transfusion were independently related with long-term prognosis in patients with HCC following curative surgery.

Keywords: Blood transfusion, Hepatocellular carcinoma, Low SMI

\footnotetext{
*Correspondence: t.abe.hiroshima@gmail.com

'Department of Surgery, Onomichi General Hospital, 1-10-23 Hirahara, Onomichi, Hiroshima, Japan

Full list of author information is available at the end of the article
}

(c) The Author(s). 2020 Open Access This article is licensed under a Creative Commons Attribution 4.0 International License, which permits use, sharing, adaptation, distribution and reproduction in any medium or format, as long as you give appropriate credit to the original author(s) and the source, provide a link to the Creative Commons licence, and indicate if changes were made. The images or other third party material in this article are included in the article's Creative Commons licence, unless indicated otherwise in a credit line to the material. If material is not included in the article's Creative Commons licence and your intended use is not permitted by statutory regulation or exceeds the permitted use, you will need to obtain permission directly from the copyright holder. To view a copy of this licence, visit http://creativecommons.org/licenses/by/4.0/ The Creative Commons Public Domain Dedication waiver (http://creativecommons.org/publicdomain/zero/1.0/) applies to the data made available in this article, unless otherwise stated in a credit line to the data. 


\section{Background}

Hepatocellular carcinoma (HCC) is the sixth most common carcinoma and third leading cause of cancer-related deaths worldwide [1]. Progression of surgical techniques and a better understanding of liver anatomy have played an important role in suppressing intraoperative blood loss [2, 3]. However, there is still substantial risk of perioperative blood loss in patients who undergo major hepatectomy, and the need for blood transfusion remains high [2]. From the aspect of immune surveillance for cancer, we formulated the following two hypotheses why perioperative blood transfusion should be avoided: 1) allogenic blood transfusion can increase the risk of virus infection, such as hepatitis B (HBV), hepatitis C, and human immunodeficiency syndrome $[4,5]$ and 2) it increases the risk of immunological complications due to postoperative infection, possibly leading to reduced long-term survival. Several studies have revealed that perioperative blood transfusions decreased the recurrence-free survival (RFS) and overall survival (OS) of patients after hepatectomy [6, 7]. Other reports have shown that perioperative blood transfusions does not influence RFS, OS, and disease-free survival (DFS) after hepatectomy [8,9]. The influence of perioperative blood transfusion on tumor recurrence remains controversial.

Well-known prognostic variables such as tumor marker, advanced tumor stage, and vascular invasion were evaluated. Recently, tumor-associated variables and liver function have been strongly related to longterm prognosis. Honmyo et al. [10] reported that the albumin-bilirubin grade and albumin-indocyanine green evaluation grade were not only independent prognostic factors but also associated with postoperative complications. Preoperative nutritional status and immunological status were associated with postoperative complications and outcomes of patients with HCC such as obesity, Glasgow Prognostic Score (GPS) score, and neutrophil-to-lymphocyte ratio (NLR) [1114]. Sarcopenia in HCC is also a well-known factor affecting long-term prognosis, based on the age, deteriorated immune status, and tumor-bearing condition [15-17].
This retrospective study aimed to clarify the postoperative prognostic factors, especially blood transfusion and low skeletal muscle mass index (SMI), for HCC patients with Child-Pugh grade a following curative surgery.

\section{Methods \\ Patients}

Between 2005 and 2016, of the 175 patients with HCC who underwent hepatectomy at our institute, 139 patients who underwent hepatectomy for the first time were enrolled in this study. Patients with Child-Pugh grade $\mathrm{B}$ and who underwent repeat hepatectomy were excluded (Fig. 1). Following the guidelines of the Declaration of Helsinki (Fortaleza, Brazil, October 2013), this study was approved by the institutional review board of the Onomichi General Hospital (approval number: OJH201905).

\section{Perioperative blood transfusion}

Perioperative blood transfusion was defined as transfusion of red blood cells (RBCs). This study did not involve the use of other blood products such as fresh frozen plasma and platelet concentrates during the perioperative period. Perioperative blood transfusion was defined as the use of RBCs within the period of patients' hospitalization.

\section{Definition of low SMI}

SMI was measured on an axial section at the third lumber vertebra (L3), which was taken 8 weeks prior to the surgery. They were segmented using standard Hounsfield unit (HU) ranges. Skeletal muscle was measured within the range of -29 to $+150 \mathrm{HU}$, subcutaneous adipose was measured within the range of -190 to -30 $\mathrm{HU}$, and abdominal adipose was measured within the range of -150 to $-50 \mathrm{HU}$. Low SMI was defined as SMI $<52.4 \mathrm{~cm}^{2} / \mathrm{m}^{2}$ for men and $<38.5 \mathrm{~cm}^{2} / \mathrm{m}^{2}$ for women.

\section{Definition of intrahepatic metastasis and tumor number (solitary or multiple)}

Intrahepatic metastasis (IM) was defined as a tumor derived from the primary tumor and located in the same

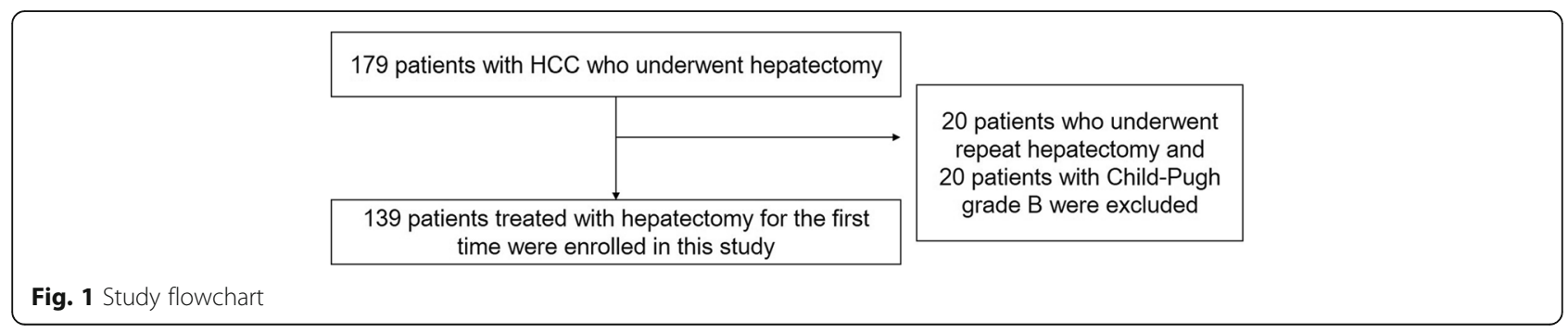


segment with the primary tumor as multiple small satellite nodules [18]. Multiple tumors were defined as the other tumor which is different from the primary tumor.

\section{Treatment and follow-up}

A follow-up blood examination to identify tumor markers was performed every 3 months after surgery for 5 years. Enhanced abdominal computed tomography (CT) was performed to rule out recurrence for 6 months. When HCC recurrence was suspected, magnetic resonance imaging was performed.

\section{Statistical analysis}

Values for continuous variables were presented as median and range. Nominal variables were expressed as numbers (\%). Non-parametric quantitative data were analysed using Mann-Whitney $U$-test. Chi-square test was performed to determine the relationship among nominal variables. The Kaplan-Meier method was used to analyze OS and DFS, and the log-rank test was used to compare different groups. Multivariate analyses were used to assess the factors that influenced OS and DFS by using the Cox regression model. $P$-values $<0.05$ were considered significant.

To overcome bias owing to the different distribution of covariates among patients from the transfusion and non-transfusion groups, propensity score-matched analysis was performed using a multiple logistic regression model to predict the probability of each patient being transfusion on the basis of clinicopathological variables. Propensity scores were calculated according to baseline characteristics such as prognostic nutritional index (PNI), $\mathrm{Hb}$, protein induced by vitamin $\mathrm{K}$ absence or antagonist-II (PIVKA-II), operation time, which were variables that differed significantly $(P$-values of $<0.05)$, based on logistic regression models for comparison with transfusion.

A 1:1 propensity score-match analysis was performed using the nearest-neighbor method to identify the impact of blood transfusion. Caliper was not set due to the small sample size. After 1:1 propensity score matching, to evaluate the discrimination and calibration abilities of propensity scores, $\mathrm{C}$ statistics and coefficient of determination of multiple logistic regression models (Nagalkerke $R^{2}$ ) and the Hosmer-Lemeshow test were used. Model of Propensity score matching of transfusion had a good coefficient of determination (Nagalkerke $R^{2}=$ 0.292), and was well calibrated (Hosmer-Lemeshow test; $p=0.798$ ) with good discrimination [C statistic $=0.821$, 95\% confidence interval (CI) $0.726-0.915, p<0.001$ ]. This One-to-one pair matching was successful $(0.523$, 95\% CI $0.340-0.705 ; p=0.808)$. Calculations were performed using the SPSS software (version 24; IBM Corp., Armonk, NY, USA).

\section{Results}

Prognostic factors for OS and RFS identified by univariate and multivariate analyses

The median postoperative follow-up duration was 2.7 years. The actual 1,3, and 5-year OS rates were 90.3, 70.0, and $59.1 \%$, respectively. The actual 1,3 , and 5 -year RFS rates were $77.2,47.9$, and $39.7 \%$, respectively. Table 1 presents the prognostic factors for OS. On univariate analysis, the following seven factors were statistically associated with poor OS: age $>80$ years $(P=0.002)$, HBV $(P=0.027)$, elevated protein induced by vitamin $\mathrm{K}$ absence or antagonist (PIVKA-II) $(P=0.009)$, IM $(P<0.001)$, low SMI $(P=0.039$; Supplemental Fig. 1a), blood transfusion $(P=0.002$; Fig. 2a), and portal vein invasion $(\mathrm{Vp})(P=0.009)$. On multivariate analysis, the following four factors were revealed as independent poor prognostic factors of OS: age $>80$ years $(\mathrm{HR}=1.979 ; P=0.035), \mathrm{HBV} \quad(\mathrm{HR}=$ $1.681 ; P=0.035), \mathrm{IM}(\mathrm{HR}=3.675 ; P<0.001)$ and low SMI $(H R=2.006 ; P=0.046)$. Table 2 presents the prognostic factors for RFS. On univariate analysis, the following six variables were associated with poor RFS: elevated PIVKA-II $(P=0,048)$, elevated $\alpha$-fetoprotein (AFP) $(P=0.036)$, tumor number $(P=0.025)$, IM $(P<$ $0.001), \mathrm{Vp}(P=0.016)$, and blood transfusion $(P=$ 0.008 ; Fig. $2 \mathrm{~b})$. On multivariate analysis, the following three factors were revealed as the poor prognostic factors of RFS: tumor number $(\mathrm{HR}=1.810 ; P=0.041)$, IM $(\mathrm{HR}=4.115 ; P<0.001)$ and blood transfusion $(\mathrm{HR}=2.288 ; P=0.008)$. There was no significant difference in RFS between patients with low SMI and those with high SMI. ( $P=0.335$; Supplemental Fig. $1 b)$.

\section{Characteristics of low SMI patients and high SMI patients with HCC}

Supplemental Table 1 provides a comparison of the perioperative characteristics between low SMI and high SMI patients with HCC. The male ratio in the low SMI group was higher than that in the high SMI group. The number of patients with low body mass index was significantly higher in the low SMI group than that in high SMI group. No significant differences were observed for age, NLR, PNI, and GPS between the groups. Tumor markers, liver function, and tumor-related factors were compatible between the two groups. The pattern of recurrence and type of treatment were not different between the two groups.

\section{Characteristics of patients with HCC who received blood transfusion and those who did not receive blood transfusion}

Table 3 presents the perioperative characteristics of the blood transfusion group and non-transfusion group with HCC. PNI of the transfusion group was lower than that of the non-transfusion group. With 
Table 1 Prognostic factors for overall survival identified by univariate and multivariate analyses $(n=139)$

\begin{tabular}{|c|c|c|c|c|c|c|c|}
\hline \multirow[b]{2}{*}{ Variables } & \multirow[b]{2}{*}{ n (\%) } & \multirow[b]{2}{*}{ 3-year survival } & \multirow[b]{2}{*}{ 5-year survival } & \multirow{2}{*}{$\begin{array}{l}\text { Univariate } \\
P \text {-value }\end{array}$} & \multicolumn{3}{|c|}{ Multivariate } \\
\hline & & & & & $\mathrm{HR}$ & $95 \% \mathrm{Cl}$ & $P$-value \\
\hline Male sex & $110(79 \%)$ & $65.4 \%$ & $56.7 \%$ & 0.258 & & & \\
\hline Female sex & $29(21 \%)$ & $88.5 \%$ & $68.5 \%$ & & & & \\
\hline \multicolumn{8}{|l|}{ Age (years) } \\
\hline$\leq \mathbf{8 0}$ & 109 (78\%) & $74.1 \%$ & $66.8 \%$ & 0.002 & 1.979 & $1.050-3.732$ & 0.035 \\
\hline$>80$ & 30 (22\%) & $54.1 \%$ & $33.7 \%$ & & & & \\
\hline \multicolumn{8}{|l|}{ BMI $\left(\mathrm{kg} / \mathrm{m}^{2}\right)$} \\
\hline$>25$ & $34(25 \%)$ & $74.4 \%$ & $63.0 \%$ & 0.441 & & & \\
\hline$\leq 25$ & 105 (75\%) & $68.7 \%$ & $58.1 \%$ & & & & \\
\hline \multicolumn{8}{|l|}{ ALBI } \\
\hline grade III & $30(22 \%)$ & $64.2 \%$ & $55.0 \%$ & 0.677 & & & \\
\hline$<$ grade III & 109 (78\%) & $71.4 \%$ & $59.6 \%$ & & & & \\
\hline \multicolumn{8}{|l|}{ HBV } \\
\hline$(+)$ & 27 (19\%) & $78.3 \%$ & $78.3 \%$ & 0.027 & 1.681 & $1.037-2.726$ & 0.035 \\
\hline$(-)$ & 112 (81\%) & $67.9 \%$ & $52.7 \%$ & & & & \\
\hline \multicolumn{8}{|l|}{ HCV } \\
\hline$(+)$ & $70(50 \%)$ & $71.5 \%$ & $59.4 \%$ & 0.668 & & & \\
\hline$(-)$ & $69(50 \%)$ & $68.0 \%$ & $58.8 \%$ & & & & \\
\hline \multicolumn{8}{|l|}{ DM } \\
\hline$(+)$ & 29 (21\%) & $75.3 \%$ & $58.6 \%$ & 0.582 & & & \\
\hline$(-)$ & 110 (79\%) & $68.6 \%$ & $58.6 \%$ & & & & \\
\hline \multicolumn{8}{|l|}{ NLR } \\
\hline$\geq 4$ & $13(9 \%)$ & $52.6 \%$ & $52.6 \%$ & 0.257 & & & \\
\hline$<4$ & 126 (91\%) & $71.3 \%$ & $60.0 \%$ & & & & \\
\hline \multicolumn{8}{|l|}{$\operatorname{PLT}\left(\times 10^{4} / \mu \mathrm{L}\right)$} \\
\hline normal (13-35) & 97 (70\%) & $73.4 \%$ & $60.7 \%$ & 0.582 & & & \\
\hline abnormal & $42(30 \%)$ & $63.1 \%$ & $55.4 \%$ & & & & \\
\hline \multicolumn{8}{|l|}{$\mathrm{Hb}(\mathrm{g} / \mathrm{dL})$} \\
\hline normal (13.5-15.8) & $95(68 \%)$ & $74.2 \%$ & $63.7 \%$ & 0.094 & & & \\
\hline abnormal & $44(32 \%)$ & $61.2 \%$ & $50.1 \%$ & & & & \\
\hline \multicolumn{8}{|l|}{ PT (\%) } \\
\hline normal (70-130) & $125(90 \%)$ & $72.3 \%$ & $60.4 \%$ & 0.172 & & & \\
\hline abnormal & $14(10 \%)$ & $46.2 \%$ & $46.2 \%$ & & & & \\
\hline \multicolumn{8}{|l|}{ AST (U/L) } \\
\hline normal (13-33) & $71(51 \%)$ & $78.6 \%$ & $59.9 \%$ & 0.086 & & & \\
\hline abnormal & $68(49 \%)$ & $61.1 \%$ & $56.5 \%$ & & & & \\
\hline \multicolumn{8}{|l|}{$\mathrm{ALT}(\mathrm{U} / \mathrm{L})$} \\
\hline normal (8-42) & 100 (72\%) & $73.2 \%$ & $59.7 \%$ & 0.298 & & & \\
\hline abnormal & $39(28 \%)$ & $61.8 \%$ & $57.0 \%$ & & & & \\
\hline \multicolumn{8}{|l|}{ CHE (g/dL) } \\
\hline normal (229-521) & 77 (55\%) & $74.6 \%$ & $64.0 \%$ & 0.110 & & & \\
\hline abnormal & $62(45 \%)$ & $63.6 \%$ & $52.6 \%$ & & & & \\
\hline \multicolumn{8}{|l|}{ Alb (g/dL) } \\
\hline normal (4.0-5.0) & $115(83 \%)$ & $72.2 \%$ & $60.3 \%$ & 0.165 & & & \\
\hline
\end{tabular}


Table 1 Prognostic factors for overall survival identified by univariate and multivariate analyses $(n=139)$ (Continued)

\begin{tabular}{|c|c|c|c|c|c|c|c|}
\hline \multirow[b]{2}{*}{ Variables } & \multirow[b]{2}{*}{ n (\%) } & \multirow[b]{2}{*}{ 3-year survival } & \multirow[b]{2}{*}{ 5-year survival } & \multirow{2}{*}{$\begin{array}{l}\text { Univariate } \\
P \text {-value }\end{array}$} & \multicolumn{3}{|c|}{ Multivariate } \\
\hline & & & & & $\mathrm{HR}$ & $95 \% \mathrm{Cl}$ & $P$-value \\
\hline abnormal & $24(17 \%)$ & $58.4 \%$ & $51.9 \%$ & & & & \\
\hline \multicolumn{8}{|l|}{ T-chol (mg/dL) } \\
\hline normal (128-219) & $118(85 \%)$ & $71.7 \%$ & $59.1 \%$ & 0.732 & & & \\
\hline abnormal & $20(14 \%)$ & $66.9 \%$ & $66.9 \%$ & & & & \\
\hline \multicolumn{8}{|l|}{ PIVKA-II (mAU/mL) } \\
\hline normal $(<40)$ & $62(45 \%)$ & $81.0 \%$ & $74.7 \%$ & 0.009 & 1.852 & $0.940-3.649$ & 0.075 \\
\hline abnormal & 77 (55\%) & $60.8 \%$ & $45.7 \%$ & & & & \\
\hline \multicolumn{8}{|l|}{$\operatorname{AFP}(\mathrm{ng} / \mathrm{mL})$} \\
\hline normal (> 10) & $68(49 \%)$ & $73.8 \%$ & $66.9 \%$ & 0.126 & & & \\
\hline abnormal & $68(49 \%)$ & $66.2 \%$ & $51.4 \%$ & & & & \\
\hline \multicolumn{8}{|l|}{ Tumor number } \\
\hline solitary & 113 (81\%) & $70.6 \%$ & $65.5 \%$ & 0.167 & & & \\
\hline multiple & $26(19 \%)$ & $67.9 \%$ & $37.0 \%$ & & & & \\
\hline \multicolumn{8}{|l|}{ Tumor size } \\
\hline $3 \mathrm{~cm}<$ & $71(51 \%)$ & $68.0 \%$ & $59.5 \%$ & 0.185 & & & \\
\hline$\leq 3 \mathrm{~cm}$ & $54(39 \%)$ & $78.5 \%$ & $71.5 \%$ & & & & \\
\hline Poor differentiation & $20(14 \%)$ & $73.7 \%$ & $48.4 \%$ & 0.545 & & & \\
\hline Others (well, moderately) & 119 (86\%) & $69.2 \%$ & $61.1 \%$ & & & & \\
\hline \multicolumn{8}{|l|}{ IM } \\
\hline$(+)$ & 19 (14\%) & $34.1 \%$ & $22.7 \%$ & $<0.001$ & 3.675 & $1.848-7.308$ & $<0.001$ \\
\hline$(-)$ & $120(86 \%)$ & $77.1 \%$ & $66.0 \%$ & & & & \\
\hline \multicolumn{8}{|l|}{$V p$} \\
\hline$(+)$ & $26(19 \%)$ & $49.6 \%$ & $42.5 \%$ & 0.009 & 1.700 & $0.940-3.649$ & 0.130 \\
\hline$(-)$ & 113 (81\%) & $74.6 \%$ & $62.8 \%$ & & & & \\
\hline Low SMI & $86(62 \%)$ & $63.6 \%$ & $52.4 \%$ & 0.039 & 2.006 & $1.012-3.974$ & 0.046 \\
\hline High SMI & $53(38 \%)$ & $80.9 \%$ & $70.5 \%$ & & & & \\
\hline \multicolumn{8}{|l|}{ Blood transfusion } \\
\hline$(+)$ & $22(16 \%)$ & $40.0 \%$ & $30.0 \%$ & 0.002 & 2.012 & $1.001-4.045$ & 0.050 \\
\hline$(-)$ & 117 (84\%) & $75.5 \%$ & $64.3 \%$ & & & & \\
\hline
\end{tabular}

Variables in bold are statistically significant $(P<0.05)$

Abbreviations: $B M I$ Body mass index, $A L B I$ albumin-bilirubin, $H B V$ hepatitis type $B, H C V$ hepatitis type $C, D M$ diabetes mellitus, NLR neutrophil-to-lymphocyte ratio, PLT platelets, $H b$ hemoglobin, PT prothrombin time, AST aspartate aminotransferase, ALT alanine aminotransferase, $C H E$ cholinesterase, $A / b$ albumin, $T$-chol totalcholesterol, PIVKAIl protein induced by vitamin K absence or antagonist-II, AFP a-fetoprotein, IM intrahepatic metastasis, VP portal vain invasion, SMI skeletal muscle mass index

regard to the laboratory data, albumin levels and PIVKA-II were significantly higher in the transfusion group than those in the non-transfusion group. The preoperative hemoglobin level was significantly lower in the patients who received blood transfusion than in those who did not. No significant differences were observed in the tumor-related factors between the two groups. Operation time and recurrence ratio were significantly higher in the transfusion group than those in the non-transfusion group. Even after the propensity-matched analysis, blood transfusion showed a negative impact on RFS.

\section{Discussion}

Several studies examining the prognosis of HCC patients following surgery have traditionally emphasized the effects of tumor-specific variables, lymph node metastasis, IM, and vascular invasion [19-22]. Undoubtedly, tumorspecific factors were related to the long-term prognosis; however, patient-related factors such as the immunological variables and sarcopenia have been reported as significant factors affecting the long-term prognosis. In the present study, low SMI and perioperative blood transfusion had a strong impact on long-term prognosis. Preoperative detection of low SMI is important to assess 


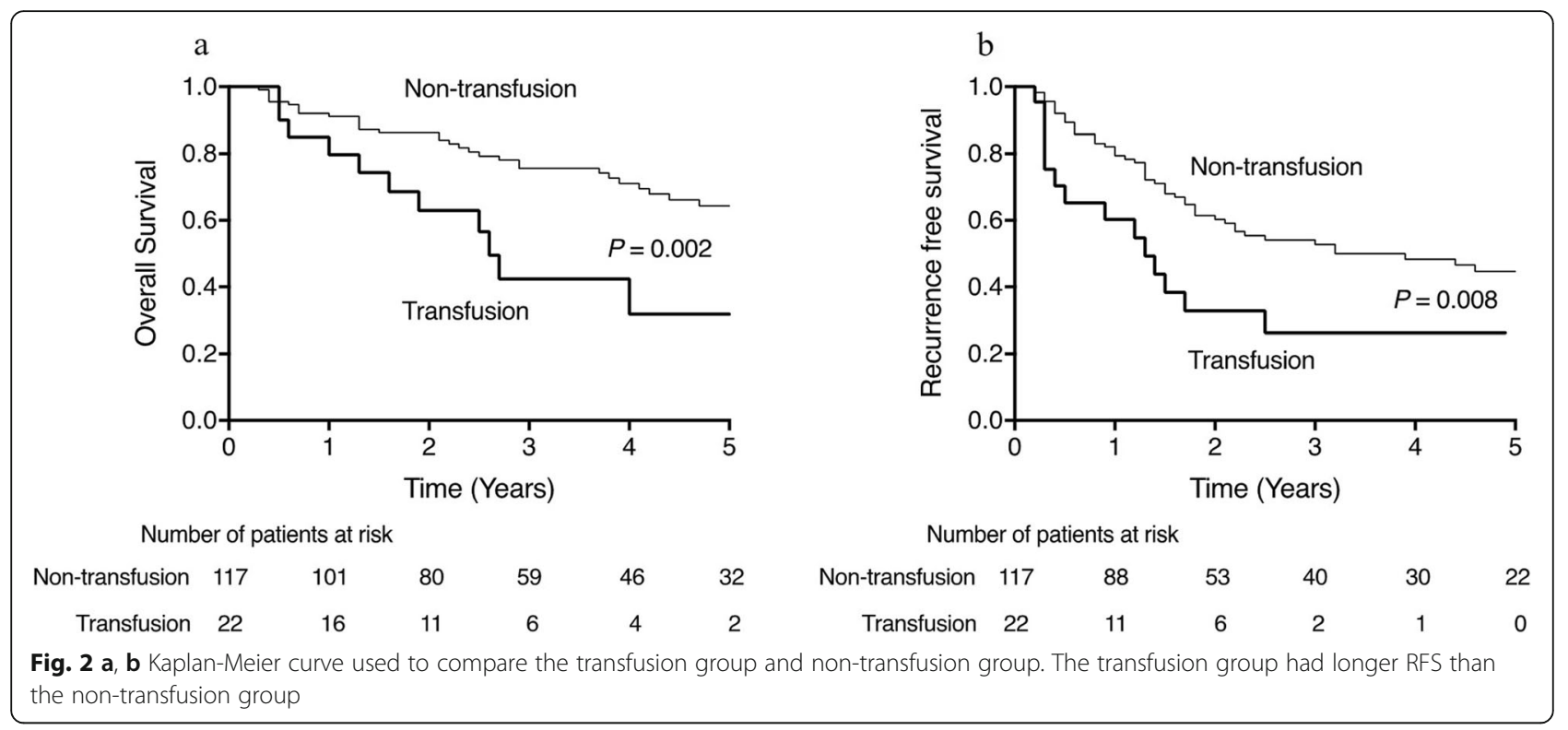

the prognosis in patients with HCC after curative surgery. Frailty is widely used as a metric of patient physiological reserve and overall health status. Recent studies have shown that skeletal muscle mass, which can be measured on CT cross-sectional imaging, is a marker of frailty and is used to detect sarcopenia [23, 24]. On the other hand, the European Working Group on Sarcopenia in Older People recommended that sarcopenia should be diagnosed if both low muscles and low muscle function are present [25]. The efficacy of preoperative exercise and nutrition in patients with sarcopenia remains unclear; several studies have demonstrated that aerobic and resistance exercises are more effective in improving upper lower body muscle strength than the usual treatment $[26,27]$. In addition, the skeletal muscle was recently recognized as an endocrine organ [28]. Interleukin (IL)-6, which may influence liver metabolism, is released from the skeletal muscle. IL-6 has already been identified as a factor with biological effects in patients with liver fibrosis and HCC [28]. Insulin-like growth factor (IGF)-1 was confirmed as a stimulatory factor in the development and regulation of skeletal muscle mass [28]. IGF-1 is mainly produced by the liver. Therefore, serum IGF-1 levels were low in patients with sarcopenia, and low IGF-1 levels result in the progression of HCC. Hence, there is a relationship between sarcopenia and HCC prognosis. Preventing muscle wasting is important for improving the prognosis of patients with HCC. In particular, patients with liver cirrhosis have decreased liver function, glycogen stores, and protein synthesis due to liver atrophy. In our study, we found no significant difference between the patients with low and high SMIs. Regardless of the equivalent recurrence rates, the patients with low SMI showed poorer OS than those with high SMI. This is affected by the treatment strategy for HCC recurrence; that is, the patients with low SMI did not undergo a second hepatectomy unlike those with high SMI. Their consumption of amino acids from the skeletal muscle as an energy source increases, which causes progression of sarcopenia $[29,30]$. There is a report showing that perioperative nutritional therapy using branched-chain amino acids improves OS of patients with cirrhosis and sarcopenia [31]. Multidisciplinary approach to overcome sarcopenia would improve the longterm prognosis of patients with HCC following curative surgery.

Several previous studies have demonstrated that blood transfusion had a negative impact on the prognosis of HCC patients $[6,32]$. In line with Harada et al.'s study, this study suggests that blood transfusion was associated with HCC recurrence after hepatectomy in patients with Child-Pugh class A. Recent studies have reported that transfusion-related immunomodulation affects the prognosis of patients who received blood transfusion. RBCs transfusion was referred to as an immune system suppressor and has been linked to tumor recurrence [33]. The absolute peripheral blood lymphocyte count of patients who underwent blood transfusion is lower than that of patients who did not undergo blood transfusion [34]. There is one study that demonstrated that the natural killer cell activity of patients who underwent blood transfusion decreased on postoperative day 7 [35], leading to decreased tumor suppression. Additionally, blood transfusion cause secondary iron overload, which may accelerate the progression of liver fibrosis and recurrence of HCC [36]. The long-term prognosis of patients with distal cholangiocarcinoma who received 
Table 2 Prognostic factors for recurrence-free survival identified by univariate and multivariate analyses $(n=139)$

\begin{tabular}{|c|c|c|c|c|c|c|c|}
\hline \multirow[b]{2}{*}{ Variables } & \multirow[b]{2}{*}{ n (\%) } & \multirow[b]{2}{*}{ 3-year survival } & \multirow[b]{2}{*}{ 5-year survival } & \multirow{2}{*}{$\begin{array}{l}\text { Univariate } \\
P \text {-value }\end{array}$} & \multicolumn{3}{|c|}{ Multivariate } \\
\hline & & & & & HR & $95 \% \mathrm{Cl}$ & $P$-value \\
\hline Male sex & $110(79 \%)$ & $45.8 \%$ & $41.2 \%$ & 0.180 & & & \\
\hline Female sex & $29(21 \%)$ & $56.6 \%$ & $40.4 \%$ & & & & \\
\hline \multicolumn{8}{|l|}{ Age (years) } \\
\hline$\leq 80$ & 109 (78\%) & $24.9 \%$ & $24.9 \%$ & 0.084 & & & \\
\hline$>80$ & $30(22 \%)$ & $52.4 \%$ & $45.2 \%$ & & & & \\
\hline \multicolumn{8}{|l|}{ BMI $\left(\mathrm{kg} / \mathrm{m}^{2}\right)$} \\
\hline$>25$ & $34(25 \%)$ & $48.0 \%$ & $48.0 \%$ & 0.699 & & & \\
\hline$\leq 25$ & $105(75 \%)$ & $48.3 \%$ & $39.3 \%$ & & & & \\
\hline \multicolumn{8}{|l|}{ ALBI } \\
\hline grade III & $30(22 \%)$ & $49.5 \%$ & $44.6 \%$ & 0.708 & & & \\
\hline$<$ grade III & 109 (78\%) & $47.7 \%$ & $40.1 \%$ & & & & \\
\hline \multicolumn{8}{|l|}{ HBV } \\
\hline$(+)$ & 27 (19\%) & $63.2 \%$ & $47.7 \%$ & 0.236 & & & \\
\hline$(-)$ & $112(81 \%)$ & $44.1 \%$ & $37.7 \%$ & & & & \\
\hline \multicolumn{8}{|l|}{$\mathrm{HCV}$} \\
\hline$(+)$ & $70(50 \%)$ & $40.8 \%$ & $38.6 \%$ & 0.163 & & & \\
\hline$(-)$ & $69(50 \%)$ & $56.4 \%$ & $44.2 \%$ & & & & \\
\hline \multicolumn{8}{|l|}{ DM } \\
\hline$(+)$ & 29 (21\%) & $57.5 \%$ & $43.6 \%$ & 0.674 & & & \\
\hline$(-)$ & $110(79 \%)$ & $45.2 \%$ & $39.9 \%$ & & & & \\
\hline \multicolumn{8}{|l|}{ NLR } \\
\hline$\geq 4$ & $13(9 \%)$ & $19.4 \%$ & $19.4 \%$ & 0.279 & & & \\
\hline$<4$ & $126(91 \%)$ & $49.9 \%$ & $42.5 \%$ & & & & \\
\hline \multicolumn{8}{|l|}{$\operatorname{PLT}\left(\times 10^{4} / \mu \mathrm{L}\right)$} \\
\hline normal (13-35) & 97 (70\%) & $50.4 \%$ & $42.4 \%$ & 0.595 & & & \\
\hline abnormal & $42(30 \%)$ & $44.1 \%$ & $39.2 \%$ & & & & \\
\hline \multicolumn{8}{|l|}{$\mathrm{Hb}(\mathrm{g} / \mathrm{dL})$} \\
\hline normal (13.5-15.8) & $95(68 \%)$ & $50.5 \%$ & $41.6 \%$ & 0.795 & & & \\
\hline abnormal & 44 (32\%) & $44.3 \%$ & $40.9 \%$ & & & & \\
\hline \multicolumn{8}{|l|}{ PT (\%) } \\
\hline normal (70-130) & 125 (90\%) & $50.5 \%$ & $42.5 \%$ & 0.125 & & & \\
\hline abnormal & 14 (10\%) & $28.8 \%$ & $28.8 \%$ & & & & \\
\hline \multicolumn{8}{|l|}{ AST (U/L) } \\
\hline normal (13-33) & 71 (51\%) & $45.6 \%$ & $33.9 \%$ & 0.888 & & & \\
\hline abnormal & 68 (49\%) & $51.1 \%$ & $48.1 \%$ & & & & \\
\hline \multicolumn{8}{|l|}{$\mathrm{ALT}(\mathrm{U} / \mathrm{L})$} \\
\hline normal (8-42) & 100 (72\%) & $48.8 \%$ & $41.0 \%$ & 0.770 & & & \\
\hline abnormal & 39 (28\%) & $46.8 \%$ & $40.9 \%$ & & & & \\
\hline \multicolumn{8}{|l|}{ CHE (g/dL) } \\
\hline normal (229-521) & 77 (55\%) & $53.8 \%$ & $44.9 \%$ & 0.251 & & & \\
\hline abnormal & 62 (45\%) & $41.7 \%$ & $36.4 \%$ & & & & \\
\hline \multicolumn{8}{|l|}{ Alb (g/dL) } \\
\hline normal (4.0-5.0) & $115(83 \%)$ & $48.5 \%$ & $39.8 \%$ & 0.878 & & & \\
\hline
\end{tabular}


Table 2 Prognostic factors for recurrence-free survival identified by univariate and multivariate analyses $(\mathrm{n}=139)($ Continued)

\begin{tabular}{|c|c|c|c|c|c|c|c|}
\hline \multirow[b]{2}{*}{ Variables } & \multirow[b]{2}{*}{ n (\%) } & \multirow[b]{2}{*}{ 3-year survival } & \multirow[b]{2}{*}{ 5-year survival } & \multirow{2}{*}{$\begin{array}{l}\text { Univariate } \\
P \text {-value }\end{array}$} & \multicolumn{3}{|c|}{ Multivariate } \\
\hline & & & & & HR & $95 \% \mathrm{Cl}$ & $P$-value \\
\hline abnormal & $24(17 \%)$ & $46.7 \%$ & $46.7 \%$ & & & & \\
\hline \multicolumn{8}{|l|}{ T-chol (mg/dL) } \\
\hline normal (128-219) & $118(85 \%)$ & $49.4 \%$ & $43.0 \%$ & 0.907 & & & \\
\hline abnormal & $20(14 \%)$ & $42.1 \%$ & $31.6 \%$ & & & & \\
\hline \multicolumn{8}{|l|}{ PIVKA-II (mAU/mL) } \\
\hline normal $(<40)$ & $62(45 \%)$ & $61.0 \%$ & $51.0 \%$ & 0.048 & 1.321 & $0.778-2.240$ & 0.320 \\
\hline abnormal & 77 (55\%) & $37.7 \%$ & $33.0 \%$ & & & & \\
\hline \multicolumn{8}{|l|}{$\operatorname{AFP}(\mathrm{ng} / \mathrm{mL})$} \\
\hline normal $(>10)$ & $68(49 \%)$ & $58.8 \%$ & $48.9 \%$ & 0.036 & 1.612 & $0.960-2.707$ & 0.071 \\
\hline abnormal & $68(49 \%)$ & $38.7 \%$ & $33.5 \%$ & & & & \\
\hline \multicolumn{8}{|l|}{ Tumor number } \\
\hline solitary & $113(81 \%)$ & $51.8 \%$ & $44.5 \%$ & 0.025 & 1.810 & $1.025-3.197$ & 0.041 \\
\hline multiple & $26(19 \%)$ & $31.4 \%$ & $18.8 \%$ & & & & \\
\hline \multicolumn{8}{|l|}{ Tumor size } \\
\hline $3 \mathrm{~cm}<$ & $71(51 \%)$ & $49.5 \%$ & $43.4 \%$ & 0.938 & & & \\
\hline$\leq 3 \mathrm{~cm}$ & 54 (39\%) & $52.6 \%$ & $42.7 \%$ & & & & \\
\hline Poor differentiation & $20(14 \%)$ & $42.1 \%$ & $28.1 \%$ & 0.337 & & & \\
\hline Others (well, moderately) & $119(86 \%)$ & $49.3 \%$ & $43.6 \%$ & & & & \\
\hline \multicolumn{8}{|l|}{ IM } \\
\hline$(+)$ & 19 (14\%) & $5.6 \%$ & $5.6 \%$ & $<0.001$ & 4.115 & $2.255-7.510$ & $<0.001$ \\
\hline$(-)$ & $120(86 \%)$ & $56.1 \%$ & $47.5 \%$ & & & & \\
\hline \multicolumn{8}{|l|}{$V p$} \\
\hline$(+)$ & $26(19 \%)$ & $28.4 \%$ & $28.4 \%$ & 0.016 & 1.490 & $0.824-2.695$ & 0.187 \\
\hline$(-)$ & $113(81 \%)$ & $52.8 \%$ & $43.5 \%$ & & & & \\
\hline Low SMI & $86(62 \%)$ & $46.1 \%$ & $39.8 \%$ & 0.335 & & & \\
\hline High SMI & $53(38 \%)$ & $51.9 \%$ & $43.9 \%$ & & & & \\
\hline \multicolumn{8}{|l|}{ Blood transfusion } \\
\hline$(+)$ & $22(16 \%)$ & $24.6 \%$ & $24.6 \%$ & 0.008 & 2.288 & $1.244-4.207$ & 0.008 \\
\hline$(-)$ & 117 (84\%) & $52.4 \%$ & $44.4 \%$ & & & & \\
\hline
\end{tabular}

Variables in bold are statistically significant $(P<0.05)$. Abbreviations: BMI, Body mass index; ALBI, albumin-bilirubin; HBV, hepatitis type B; HCV, hepatitis type C; DM, diabetes mellitus; NLR, neutrophil-to-lymphocyte ratio; PLT, platelets; Hb, hemoglobin; PT, prothrombin time; AST, aspartate aminotransferase; ALT, alanine aminotransferase; CHE, cholinesterase; Alb, albumin; T-chol, total-cholesterol; PIVKAll, protein induced by vitamin K absence or antagonist-Il; AFP, a-fetoprotein; IM, intrahepatic metastasis; $\mathrm{Vp}$, portal vain invasion; SMI, skeletal muscle mass index

perioperative RBCs transfusion was poorer than those who did not receive RBCs transfusion [37]. Moreover, intraoperative RBCs transfusion was associated with poor OS in patients with periampullary cancer who underwent pancreaticoduodenectomy [38]. In our study, the patients in the blood transfusion group required longer operation time and had a larger volume of intraoperative blood loss than those in the non-transfusion group even after the propensity-matched analysis. Blood transfusion had a negative impact on RFS. Hence, it is important to avoid unnecessary blood transfusion and intraoperative blood loss to maintain the normal function of the host immune system.
This retrospective, single-center study had a limited sample size. Future prospective cohort studies involving multiple institutions should be performed to confirm our results. The patients who underwent blood transfusion were significantly associated with preoperative anemia as compared with those who did not receive blood transfusion. The several biases were still attributed to the enforcement of blood transfusion even after the propensity-matched analysis.

\section{Conclusion}

In conclusion, low SMI and perioperative blood transfusion were associated with long-term prognosis of $\mathrm{HCC}$ 
Table 3 Comparison of the characteristics of patients who underwent transfusion and those who did not undergo transfusion with data reported for the whole study series and for one-to-one score-matched pair

\begin{tabular}{|c|c|c|c|c|c|c|c|c|}
\hline & Whole study s & & & & & Propensity score & natched series & \\
\hline & $\begin{array}{l}\text { All } \\
\text { patients } \\
(n=139)\end{array}$ & $\begin{array}{l}\text { Transfusion } \\
(n=22)\end{array}$ & $\begin{array}{l}\text { Non-transfusion } \\
(n=117)\end{array}$ & $P$-value & $\begin{array}{l}\text { All } \\
\text { patients } \\
(n=40)\end{array}$ & $\begin{array}{l}\text { Transfusion } \\
(n=20)\end{array}$ & $\begin{array}{l}\text { Non-transfusion } \\
(\mathrm{n}=20)\end{array}$ & $P$-value \\
\hline Male sex & $110(79 \%)$ & $18(82 \%)$ & $92(79 \%)$ & 1.000 & $31(78 \%)$ & $16(80 \%)$ & $15(75 \%)$ & 1.000 \\
\hline Age (years) $\geq 70$ & $88(63 \%)$ & $16(73 \%)$ & $72(62 \%)$ & 0.348 & $27(68 \%)$ & $15(75 \%)$ & $12(60 \%)$ & 0.501 \\
\hline BMI $\left(\mathrm{kg} / \mathrm{m}^{2}\right) \geq 25.0$ & $34(25 \%)$ & $4(18 \%)$ & $30(26 \%)$ & 0.593 & $10(25 \%)$ & $4(20 \%)$ & $6(30 \%)$ & 0.716 \\
\hline HBV & $27(19 \%)$ & $3(14 \%)$ & $24(21 \%)$ & 0.568 & $5(13 \%)$ & $3(15 \%)$ & $2(10 \%)$ & 1.000 \\
\hline $\mathrm{HCV}$ & $70(50 \%)$ & $12(55 \%)$ & $58(50 \%)$ & 0.817 & $20(50 \%)$ & $10(50 \%)$ & $10(50 \%)$ & 1.000 \\
\hline DM & $29(21 \%)$ & $2(9 \%)$ & $27(23 \%)$ & 0.165 & $7(18 \%)$ & $2(10 \%)$ & $5(25 \%)$ & 0.407 \\
\hline NLR & $13(9 \%)$ & $1(5 \%)$ & $12(10 \%)$ & 0.481 & $4(10 \%)$ & $1(5 \%)$ & $2(10 \%)$ & 1.000 \\
\hline PNI & $11(8 \%)$ & $5(23 \%)$ & $6(5 \%)$ & 0.015 & $7(18 \%)$ & $5(25 \%)$ & $2(10 \%)$ & 0.407 \\
\hline GPS $\geq 1$ & $24(17 \%)$ & $7(32 \%)$ & $17(15 \%)$ & 0.065 & $13(33 \%)$ & $6(30 \%)$ & $7(35 \%)$ & 1.000 \\
\hline $\mathrm{Hb}(\mathrm{g} / \mathrm{dL})$ & $14.1(9.4-18.2)$ & $13.5(9.4-17.8)$ & $14.1(9.4-18.2)$ & 0.016 & $13.4(9.4-17.8)$ & $13.7(9.4-17.8)$ & $13.2(9.4-15.3)$ & 0.490 \\
\hline PLT $\left(\times 10^{4} / \mu \mathrm{L}\right)<14$ & $45(32 \%)$ & $8(36 \%)$ & $37(32 \%)$ & 0.804 & $13(33 \%)$ & $7(35 \%)$ & $6(30 \%)$ & 1.000 \\
\hline PT $(\%)<70$ & $14(10 \%)$ & $1(5 \%)$ & $13(11 \%)$ & 0.698 & $2(5 \%)$ & $1(5 \%)$ & $1(5 \%)$ & 1.000 \\
\hline T-Bil $(\mathrm{mg} / \mathrm{dL}) \geq \mathbf{1}$ & $29(21 \%)$ & $4(14 \%)$ & $25(21 \%)$ & 0.495 & $6(15 \%)$ & $3(15 \%)$ & $3(15 \%)$ & 1.000 \\
\hline AST $(U / L) \geq 38$ & $57(41 \%)$ & $11(50 \%)$ & $46(39 \%)$ & 0.357 & $19(48 \%)$ & $11(55 \%)$ & $8(40 \%)$ & 0.527 \\
\hline $\operatorname{ALT}(U / L) \geq 42$ & $41(30 \%)$ & $7(32 \%)$ & $34(29 \%)$ & 0.802 & $16(40 \%)$ & $7(35 \%)$ & $9(45 \%)$ & 0.748 \\
\hline $\operatorname{ChE}(\mathrm{g} / \mathrm{dL})<100$ & $3(2 \%)$ & $1(5 \%)$ & $2(2 \%)$ & 0.406 & $2(5 \%)$ & $1(5 \%)$ & $1(5 \%)$ & 1.000 \\
\hline Alb $(\mathrm{g} / \mathrm{dL})<4$ & $63(45 \%)$ & $12(55 \%)$ & $51(44 \%)$ & 0.361 & $26(65 \%)$ & $10(50 \%)$ & $16(80 \%)$ & 0.096 \\
\hline ICGR15 (\%) $\geq 10$ & $93(67 \%)$ & $18(82 \%)$ & $75(64 \%)$ & 0.059 & $33(83 \%)$ & $18(90 \%)$ & $15(75 \%)$ & 0.407 \\
\hline $\operatorname{AFP}(\mathrm{ng} / \mathrm{mL}) \geq 10$ & $68(49 \%)$ & $15(68 \%)$ & $53(45 \%)$ & 0.102 & $24(60 \%)$ & $13(65 \%)$ & $11(55 \%)$ & 0.748 \\
\hline $\begin{array}{l}\text { PIVKA-II } \\
(\mathrm{mAU} / \mathrm{mL}) \geq 40\end{array}$ & $96(69 \%)$ & $21(96 \%)$ & 75 (64\%) & 0.004 & $35(88 \%)$ & $19(95 \%)$ & $16(80 \%)$ & 0.342 \\
\hline Tumor diameter $>2 \mathrm{~cm}$ & $112(81 \%)$ & $20(91 \%)$ & $92(79 \%)$ & 0.249 & $37(93 \%)$ & $18(90 \%)$ & $19(95 \%)$ & 1.000 \\
\hline Tumor number & $1(1-5)$ & $1(1-5)$ & $1(1-3)$ & 0.963 & $1(1-3)$ & $1(1-3)$ & $1(1-3)$ & 0.495 \\
\hline Poor differentiation & $20(14 \%)$ & $3(14 \%)$ & $17(15 \%)$ & 1.000 & $4(10 \%)$ & $3(15 \%)$ & $1(5 \%)$ & 0.605 \\
\hline IM (+) & $19(6 \%)$ & $4(18 \%)$ & $15(13 \%)$ & 0.738 & $4(10 \%)$ & $2(10 \%)$ & $2(10 \%)$ & 1.000 \\
\hline Operation time (min) & $303(66-591)$ & $383(210-591)$ & $282(66-582)$ & $<0.001$ & $374(127-591)$ & $383(210-591)$ & $348(127-582)$ & 0.461 \\
\hline $\begin{array}{l}\text { Intraoperative } \\
\text { blood loss (g) }\end{array}$ & $506(0-6055)$ & $820(250-6055)$ & $230(0-2467)$ & $<0.001$ & $500(40-6055)$ & $820(250-6055)$ & $450(40-1181)$ & 0.002 \\
\hline Hospital stay (days) & $22(5-100)$ & $20(11-80)$ & $17(5-100)$ & 0.058 & $20(11-81)$ & $20(11-88)$ & $20(15-81)$ & 0.820 \\
\hline
\end{tabular}

patients with Child-Pugh class A after curative surgery. Low SMI as an indicator of nutritional status was considered as an independent prognostic factor in patients with HCC. Transfusion-related immune response was also strongly affected by recurrence rates in patients with HCC.

\section{Supplementary information}

Supplementary information accompanies this paper at https://doi.org/10. 1186/s12876-020-01472-z.

Additional file 1: Supplemental Fig. 1a, b. Kaplan-Meier curves for 5year recurrence-free survival rates in propensity score-matched hepatocellular carcinoma patients stratified according to transfusion. Transfusion patients are represented by the thick solid line, and nontransfusion patients are represented by the thin solid line.

Additional file 2: Supplemental Table 1. Characteristics of low SMI and high SMI patients with hepatocellular carcinoma.

\section{Abbreviations}

SMI: skeletal muscle mass index; HCC: hepatocellular carcinoma; OS: overall survival; RFS: recurrence-free survival; IM: intrahepatic metastasis; HBV: hepatitis B; DFS: disease-free survival; GPS: Glasgow Prognostic Score; NLR: neutrophil-to-lymphocyte ratio; RBCs: red blood cells; HU: Hounsfield unit; CT: computed tomography; PNI: prognostic nutritional index; PIVKAII: protein induced by vitamin $\mathrm{K}$ absence or antagonist-II; AFP: a-fetoprotein; IL: interleukin; IGF: insulin-like growth factor 


\section{Acknowledgments}

We would like to thank the Center of Life Science at Hiroshima University for allowing us to use their facilities. This research did not receive any specific grant from funding agencies in the public, commercial, or not-for-profit sectors.

\section{Authors' contributions}

$T B, T A$, and $H A$, wrote the manuscript. MH have made contributions to the interpretation of data. TK, MN, $\mathrm{HO}$, and TN have substantively revised the work. All the authors read and approved the final manuscript.

\section{Funding}

This research did not receive any specific grant from funding agencies in the public, commercial, or not-for-profit sectors.

\section{Availability of data and materials}

The datasets used and/or analyzed during the current study available from the corresponding author on reasonable request.

\section{Ethics approval and consent to participate}

There is no need for consent to participate to be obtained due to retrospective study. Administrative permissions were not required to access and use the medical records described in this study. This study was authorized in advance by the institutional review board of the Onomichi General Hospital (approval number: OJH201905).

\section{Consent for publication}

Not Applicable.

\section{Competing interests}

None of the authors has any financial conflict of interest related to this manuscript.

\section{Author details}

'Department of Surgery, Onomichi General Hospital, 1-10-23 Hirahara, Onomichi, Hiroshima, Japan. ${ }^{2}$ Department of Gastroenterological and Transplant Surgery, Graduate School of Biomedical and Health Sciences, Hiroshima University, Kasumi 1-2-3 Minami-ku, Hiroshima, Japan. ${ }^{3}$ Advanced Medical Skills Training Center, Institute of Biomedical and Health Sciences, Hiroshima University, Hiroshima, Japan.

\section{Received: 9 December 2019 Accepted: 25 September 2020} Published online: 07 October 2020

\section{References}

1. Ferlay J, Shin HR, Bray F, et al. Estimates of worldwide burden of cancer in 2008: GLOBOCAN 2008. Int J Cancer. 2010;127:2893-917.

2. Jarnagin WR, Gonen M, Fong $Y$, et al. Improvement in perioperative outcome after hepatic resection: analysis of 1,803 consecutive cases over the past decade. Ann Surg. 2002;236:397-406.

3. Poon RT, Fan ST, Lo CM, et al. Improving perioperative outcome expands the role of hepatectomy in management of benign and malignant hepatobiliary diseases: analysis of 1222 consecutive patients from a prospective database. Ann Surg. 2004;240:698-708.

4. Marcucci C, Madjdpour C, Spahn DR. Allogeneic blood transfusions: benefit, risks and clinical indications in countries with a low or high human development index. Br Med Bull. 2004;70:15-28.

5. Tomimaru Y, Wada H, Marubashi S, et al. Fresh frozen plasma transfusion does not affect outcomes following hepatic resection for hepatocellular carcinoma. World J Gastroenterol. 2010;16:5603-10

6. Harada N, Shirabe K, Maeda T, et al. Blood transfusion is associated with recurrence of hepatocellular carcinoma after hepatectomy in child-Pugh class a patients. World J Surg. 2015;39:1044-51.

7. Wada $H$, Eguchi $H$, Nagano $H$, et al. Perioperative allogenic blood transfusion is a poor prognostic factor after hepatocellular carcinoma surgery: a multi-center analysis. Surg Today. 2018;48:73-9.

8. Kuroda S, Tashiro H, Kobayashi T, et al. No impact of perioperative blood transfusion on recurrence of hepatocellular carcinoma after hepatectomy. World J Surg. 2012;36:651-8.

9. Yang T, Lu J-H, Lau WY, et al. Perioperative blood transfusion does not influence recurrence-free and overall survivals after curative resection for hepatocellular carcinoma: a propensity score matching analysis. J Hepatol. 2016;64:583-93.
10. Honmyo N, Kobayashi T, Hamaoka M, et al. Comparison of new prognostic systems for patients with resectable hepatocellular carcinoma: albuminbilirubin grade and albumin-indocyanine green evaluation grade. Hepatol Res. 2019;49:1218-26.

11. Horino K, Beppu T, Kuroki H, et al. Glasgow prognostic score as a useful prognostic factor after hepatectomy for hepatocellular carcinoma. Int J Clin Oncol. 2013;18:829-38.

12. Harimoto N, Yoshizumi T, Shimagaki T, et al. Inflammation-based prognostic score in patients with living donor liver transplantation for hepatocellular carcinoma. Anticancer Res. 2016;36:5537-42.

13. Abe T, Tashiro H, Kobayashi $T$, et al. Glasgow prognostic score and prognosis after hepatectomy for hepatocellular carcinoma. World J Surg. 2017:41:1860-70.

14. Abe T, Amano H, Kobayashi T, et al. Preoperative neutrophil-to-lymphocyte ratio as a prognosticator in early stage pancreatic ductal adenocarcinoma. Eur J Surg Oncol. 2018:44:1573-9.

15. Voron T, Tselikas L, Pietrasz D, et al. Sarcopenia impacts on short-and longterm results of hepatectomy for hepatocellular carcinoma. Ann Surg. 2015; 261:1173-83.

16. Kamachi S, Mizuta T, Otsuka T, et al. Sarcopenia is a risk factor for the recurrence of hepatocellular carcinoma after curative treatment. Hepat Res. 2016:46:201-8.

17. Harimoto N, Shirabe K, Yamashita Yl, et al. Sarcopenia as a predictor of prognosis in patients following hepatectomy for hepatocellular carcinoma. Br J Surg. 2013;100:1523-30.

18. Morimoto $\mathrm{O}$, Nagano $\mathrm{H}$, Sakon M, et al. Diagnosis of intrahepatic metastasis and multicentric carcinogenesis by microsatellite loss of heterozygosity in patients with multiple and recurrent hepatocellular carcinomas. J Hepatol. 2003;39:215-21

19. Hao $S$, Fan $P$, Chen $S$, et al. Distinct recurrence risk factors for intrahepatic metastasis and multicenter occurrence after surgery in patients with hepatocellular carcinoma. J Gastrointest Surg. 2017:21:312-20.

20. Kim JM, Kwon C, Joh J-W, et al. Intrahepatic metastasis is more risky than multiple occurrence in hepatocellular carcinoma patients after curative liver resection. Hepato-gastroenterology. 2015;62:399-404

21. Tsai T-J, Chau G-Y, Lui W-Y, et al. Clinical significance of microscopic tumor venous invasion in patients with resectable hepatocellular carcinoma. Surgery. 2000;127:603-8

22. Esnaola NF, Lauwers GY, Mirza NQ, et al. Predictors of microvascular invasion in patients with hepatocellular carcinoma who are candidates for orthotopic liver transplantation. J Gastrointest Surg. 2002;6:224-32.

23. Mitsiopoulos N, Baumgartner R, Heymsfield S, et al. Cadaver validation of skeletal muscle measurement by magnetic resonance imaging and computerized tomography. J Appl Physiol. 1998;85:115-22.

24. Dodson RM, Firoozmand A, Hyder O, et al. Impact of sarcopenia on outcomes following intra-arterial therapy of hepatic malignancies. $J$ Gastrointest Surg. 2013:17:2123-32.

25. Cruz-Jentoft AJ, Baeyens JP, Bauer JM, et al. Sarcopenia: European consensus on definition and diagnosis: report of the European working group on sarcopenia in older people. Age Ageing. 2010;39:412-23.

26. Cruz-Jentoft AJ, Landi F, Schneider SM et al. Prevalence of and interventions for sarcopenia in ageing adults: a systematic review. Report of the international sarcopenia initiative (EWGSOP and IWGS). Age Ageing. 2014:43:748-59.

27. Valenzuela T. Efficacy of progressive resistance training interventions in older adults in nursing homes: a systematic review. J Am Med Dir Assoc 2012;13:418-4128.

28. Pedersen BK, Febbraio MA. Muscles, exercise and obesity: skeletal muscle as a secretory organ. Nat Rev Endocrinol. 2012;8:457.

29. Tessari P. Protein metabolism in liver cirrhosis: from albumin to muscle myofibrils. Curr Opin Clin Nutr Metab Care. 2003;6:79-85.

30. Dasarathy S. Consilience in sarcopenia of cirrhosis. J Cachexia Sarcopenia Muscle. 2012;3:225-37.

31. Kaido T, Ogawa K, Fujimoto Y, et al. Impact of sarcopenia on survival in patients undergoing living donor liver transplantation. Am J of Transplant. 2013:13:1549-56.

32. Asahara T, Katayama K, Itamoto T, et al. Perioperative blood transfusion as a prognostic indicator in patients with hepatocellular carcinoma. World J Surg. 1999;23:676-80.

33. Vamvakas EC, Blajchman MA. Deleterious clinical effects of transfusionassociated immunomodulation: fact or fiction? Blood. 2001;97:1180-95. 
34. Sugita S, Sasaki A, Iwaki K, et al. Prognosis and postoperative lymphocyte count in patients with hepatocellular carcinoma who received intraoperative allogenic blood transfusion: a retrospective study. Eur I Surg Oncol (EJSO). 2008;34:339-45.

35. Kwon AH, Matsui Y, Kamiyama Y. Perioperative blood transfusion in hepatocellular carcinomas: influence of immunologic profile and recurrence free survival. Cancer. 2001;91:771-8.

36. Itasaka $\mathrm{H}$, Yamamoto $\mathrm{K}$, Taketomi A, et al. Influence of blood transfusion on postoperative long-term liver function in patients with hepatocellular carcinoma. Hepatogastroenterology. 1995;42:465-8.

37. Lopez-Aguiar AG, Ethun CG, Pawlik TM, et al. Association of perioperative transfusion with recurrence and survival after resection of distal cholangiocarcinoma: a 10-institution study from the US extrahepatic biliary malignancy consortium. Ann Surg Oncol. 2019;26:1814-23.

38. Park HM, Park SJ, Shim JR, et al. Perioperative transfusion in pancreatoduodenectomy: the double-edged sword of pancreatic surgeons. Medicine (Baltimore). 2017;96:e9019.

\section{Publisher's Note}

Springer Nature remains neutral with regard to jurisdictional claims in published maps and institutional affiliations.

Ready to submit your research? Choose BMC and benefit from:

- fast, convenient online submission

- thorough peer review by experienced researchers in your field

- rapid publication on acceptance

- support for research data, including large and complex data types

- gold Open Access which fosters wider collaboration and increased citations

- maximum visibility for your research: over $100 \mathrm{M}$ website views per year

At $\mathrm{BMC}$, research is always in progress.

Learn more biomedcentral.com/submissions 